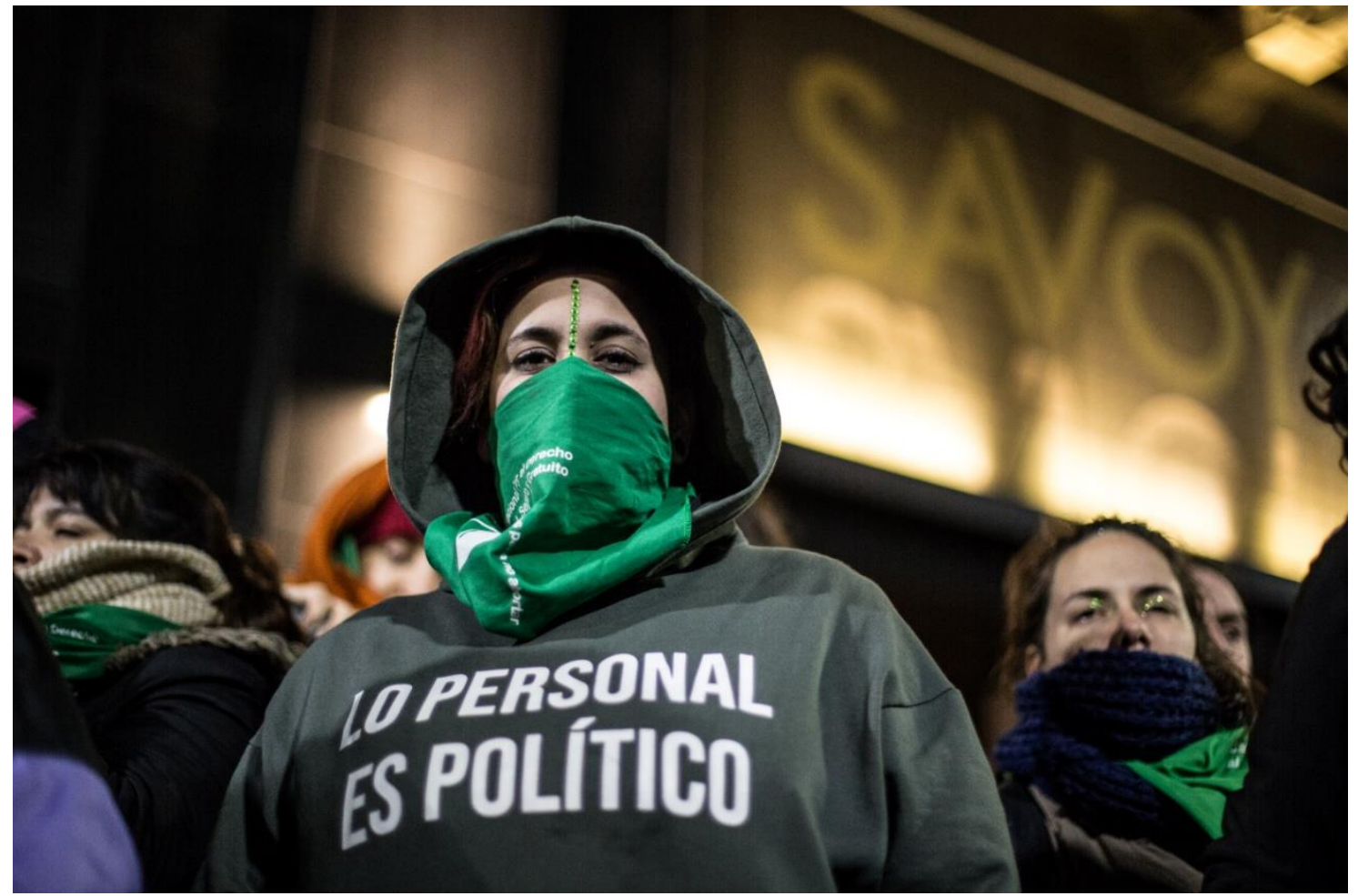

FOTOS: Irina Morán - Revista Alfilo - Periodista Feminista. Militante de Ni Una Menos Córdoba y Mujeres por un parto Respetado 


\section{EL FEMINISMO EN LAS UNIVERSIDADES ${ }^{1}$}

Resumen: Este artículo intenta pensar críticamente las categorías género y mujer en el marco del pensamiento feminista. El uso indiscriminado del concepto "género" ha terminado convirtiéndose en una aberración que, además, no presenta ningún riesgo para los quehaceres tradicionales androcéntricos de las disciplinas. Asimismo, plantea críticamente los retos y desafíos que se presentan para poder hablar de "feminismos" en la academia y en la ciencia latinoamericana. La autonomía tanto de la educación superior como del feminismo deben sostenerse en este nuevo milenio que aún no hace espacio al feminismo en sus currículas.

Palabras-clave: Universidad. Gênero. Pensamiento feminista.

\section{FEMINISMO NAS UNIVERSIDADES}

Resumo: Este artigo tenta pensar criticamente as categorias "gênero" e "mulheres" dentro da estrutura do pensamento feminista. Ele aponta que o uso indiscriminado do conceito "gênero" acabou se tornando uma aberração que, além disso, não apresenta riscos para as tarefas androcêntricas tradicionais das disciplinas acadêmicas. Não obstante aos interesses iniciais descritos, o artigo volta-se à discussão crítica dos desafios que surgem para debater os "feminismos" na academia e na ciência latino-americana. A autonomia do ensino superior e do feminismo deve ser sustentada de modo a vencer as barreiras que, ainda neste novo milênio, impedem a presença do feminismo nos currículos universitários.

Palavras-chave: Universidad. Gênero. Pensamiento feminista.

\section{INTRODUCCIÓN}

Antes que nada una breve reflexión sobre ese socorrido asunto, un tanto problemático, de lo que se ha dado en llamar "enfoque de género" o "perspectiva de género", ya que me parece importante para entender claramente qué está pasando ahí aún hoy en día. Quisiera hacer la crítica a esa forma tan socorrida de enunciar un asunto que compete a las mujeres en primerísimo lugar (aunque se diga que es de género) y que tiene o debe tener que ver con el pensamiento feminista, en cualquiera de sus corrientes. Entiendo (comparto y practico) que en determinados espacios nos veamos en la necesidad de utilizar el eufemismo "enfoque o perspectiva de género", ya que con frecuencia tenemos que montar performances o hacer teatro para que un determinado proyecto sea aceptado por el entorno social al que nos dirigimos y por la gente con poder de decisión en las instituciones.

Se ha afirmado certeramente en más de una ocasión que el concepto de género es uno de los grandes "descubrimientos" de la teorización. Este concepto ha

\footnotetext{
${ }^{1}$ Partes de este texto fueron publicadas previamente como "Posibilidades y retos de la investigación feminsta en México", Regiones. Suplemento de antropología, No 36, 20 enero del 2009. http://www.suplementoregiones.org

${ }^{2}$ Profesora-investigadora, Universidad Autónoma Metropolitana-Xochimilco, México y Coordinadora del Doctorado en Estudios Feministas. Autora de Desnudo y arte, Bogotá, Desde Abajo, 2018; Mujeres en el arte popular. De promesas, traiciones, monstruos y celebridades, México UAM/Conaculta-FONCA, 2005 y de Frida Kahlo. Mujer ideología y arte, Barcelona, Icaria, Colección Antrazyt 70, 3era. ed., 2003, entre otros.
}

Momento: diálogos em educação, E-ISSN 2316-3100, v. 28, n. 3, p. 337-349, set./dez, 2018. 
revolucionado a las ciencias, a todas ellas, aún a las más impermeables como la filosofía. Pero, su uso indiscriminado y a modo de llave maestra que abre todas las puertas, se ha convertido en una aberración. Ojalá no tuviéramos ya que esconder, que barrer a las mujeres fuera del escenario con la varita mágica del género. Ojalá, pudiéramos hablar, escribir, investigar libremente sobre la mujer, sobre las mujeres, sin que nos avergonzara tanto. Es por ello que sacamos a relucir al género y desaparecemos al incómodo y siempre devaluadísimo concepto mujer; en virtud de esto mismo, es importante aprender a que no nos sentirnos mal de hablar en femenino y, siempre que venga al caso, se privilegie la palabra mujeres y no género.

Lo que considero importante es que hagamos uso de los conceptos en su gran variedad. Tenemos el de género y hay que usarlo, usarlo bien. Pero también está el de feminismo o feminismos del cual a menudo no se quiere ni escuchar hablar o el de mujer y mujeres. Si se quiere hacer investigación rigurosa, también es preciso usar los conceptos con rigor. Si se quiere hacer investigación feminista, pero sin decirlo, resulta bastante penoso. Por otro lado, si lo que se quiere es simplemente estar dizque "a la moda", entonces se utiliza el concepto de género sin ninguna pretensión feminista, sino únicamente con el afán de aparentar una política correcta, cuando en realidad se trata de una política bastante incorrecta. Es una cuestión política oportunista y que en el fondo no critica, no subvierte y, por lo tanto, no pretende transformar nada.

Todo esto no tiene solamente un carácter científico, lejos de ello, se trata también de un asunto eminentemente político. La selección de los conceptos no es un asunto solo de índole científica sino política e ideológica. Las posibilidades y los retos de una investigación con enfoque de género son diferentes a los que debe de enfrentar una investigación feminista. Los "enfoques de género" en la academia no representan un peligro real para los quehaceres tradicionales androcéntricos de las disciplinas, ya que no se cuestiona realmente la manera en que se han desarrollado, excepto en el sentido de que esta perspectiva intenta hacer visibles a las mujeres y a los hombres por igual, cuando que la igualdad es un puro espejismo. Sabemos de sobras que las claras barreras que representa el concepto mujer o peor aún, el de feminismo, caen más fácilmente si se utiliza el de género. Los programas, los centros académicos y, desde luego, las políticas públicas que pretenden "tranversalizar al género" tienen menos obstáculos que si decidieran hablar de mujeres o de feminismo.

Si observamos a tres espacios del quehacer investigativo: el académico, el de las instituciones gubernamentales y el de las organizaciones de la sociedad civil, junto con Momento: diálogos em educação, E-ISSN 2316-3100, v. 28, n. 3, p. 337-349, set./dez, 2018. 
lo que se lleva a cabo en el mundo cultural independiente, vemos que se rigen todos por los mismos principios frente a lo que vengo argumentando. Referirse a cuestiones que mencionan a los géneros es estar al día, es entrar en la modernidad (e incluso en la posmodernidad) sin cambiar gran cosa.

En la década de 1970 iniciaron los primeros seminarios académicos en América Latina interesados en los estudios sobre mujeres; hay dos que destacan: "Perspectivas femeninas en investigación social en América Latina" (1974) en Buenos Aires y el "I Simposio Mexicano Centroamericano de Investigación sobre la Mujer" (1977), organizado por la Universidad Nacional Autónoma de México (UNAM), El Colegio de México y el Instituto Nacional de Bellas Artes. Para los años ochenta, organismos internacionales como la CEPAL, la UNESCO y la Ford apoyaron encuentros y promovieron estudios sobre las mujeres en ámbitos académicos. Ahí surgieron las redes: la Asociación Latinoamericana de Estudios de la Mujer (ALACEM) y el LASA Task Force on Women (1982). En los noventa se institucionalizaron plenamente los estudios de la mujer y de género en las universidades. Actualmente, en la región se tienen registrados numerosos centros y programas universitarios dedicados a esta temática, de los cuales como la mitad están en México. Esto debería indicarnos que vamos muy bien y que seguimos siendo la vanguardia del traspatio; sin embargo, resulta claro que es demasiado escaso lo que existe.

Varios de los centros de estudios de la mujer o de género han tenido la intención de crear programas de docencia, pero la verdad es que poco se ha logrado desarrollar. En la década de 1980 todo parecía indicar que se iba a dar un salto cualitativo y que los centros de esta naturaleza iban a proliferar en todas las universidades, así como diplomados y programas de posgrado. No hubo tal. El programa de la Universidad Autónoma Metropolitana-Xochimilco, es de los pocos que se ha consolidado y no se tambalea. Contamos con una Maestría en Estudios de la Mujer que ha cumplido 20 años y un Doctorado en Estudios Feministas de reciente creación. Estos proyectos de la UAM-X tienen la gran virtud de originarse a partir de un área de investigación de donde proviene gran parte del núcleo del cuerpo docente.

Sabido es que en América Latina y el Caribe, se ha desarrollado mucho más la investigación sobre mujeres que la docencia. Ésta, parece no avanzar a la par. Durante cuatro décadas se han realizado infinidad de investigaciones sobre el quehacer de las mujeres, sobre las relaciones entre géneros, de transgéneros, o investigaciones con carácter feminista sobre distintos tópicos.

Momento: diálogos em educação, E-ISSN 2316-3100, v. 28, n. 3, p. 337-349, set./dez, 2018. 
Cuando en la década de 1980 se institucionalizó el feminismo en la academia en México las barreras eran grandes. Las autoridades no dejaban pasar fácilmente, costaba bastante introducir la temática en la currícula de las licenciaturas. Venimos de las catacumbas luego entonces lo que había que cambiar era: TODO. Empezando por el lenguaje que era (y sigue siendo, aunque un poco menos) total y absolutamente no incluyente. Hoy se reconoce un poco más que hay que cambiarlo, y en algunos aspectos ha cambiado. Los títulos que otorgaban TODAS las universidades de Nuestra América entera eran en masculino. Ello ha ido cambiando ligeramente, porque lo hemos hecho cambiar.

Al principio hubo reacciones muy adversas ante los estudios que estuvieran centrados en las mujeres, las relaciones de género o que fueran feministas. Nadie sabía que eso era un campo de estudio. Entonces, primero se tuvieron que derribar las defensas de los y las académicas renuentes y aún hoy, 40 años después poca gente considera necesario realizar investigación feminista pero, por lo menos, no oponen tanta resistencia. Una vez se dio ese paso, el siguiente fue demostrar a integrantes de las comisiones dictaminadoras que la investigación y la docencia sobre mujeres era importante y que, por lo tanto, se requería de espacios para ello. Se abrieron y no se han abierto más tal vez porque no hay más académicas interesadas en hacerlo. Tengo la sospecha de que la razón es porque no se consideran temáticas lo suficientemente importantes y necesarias. En alguna ocasión afirmé que parecería que hemos pasado de un protofeminismo a un postfeminismo sin pasar plenamente por una etapa feminista. Sin embargo, es probable que en el 2018 las cosas estén cambiando rápidamente hacia una conciencia feminista ecuménica. Pero también se obtiene una contraofensiva, un bachlash, brutal. Los feminicidios están a la orden del día en la región latinoamericana y caribeña.

Ahora bien, aún en ámbitos que no son centros y programas sobre mujeres o sobre los géneros, la investigación se desarrolla tanto en la academia como en las instituciones gubernamentales, en organizaciones de la sociedad civil y de manera independiente. En las instituciones de educación superior públicas de México, hoy en día, son pocos los impedimentos institucionales para llevar a cabo investigación sobre mujeres. En todo caso, hay universidades en las cuales no resulta fácil desarrollar la investigación en general, pues se hallan orientadas a la docencia. Pero, los organismos encargados de evaluar el quehacer académico como Conacyt, por ejemplo, tienden a evaluar esta temática como menos seria e importante comparada con el estudios del Momento: diálogos em educação, E-ISSN 2316-3100, v. 28, n. 3, p. 337-349, set./dez, 2018. 
cambio climático, el desarrollo sustentable o la migración a secas, sin género. No fue por casualidad que el feminismo entró en la academia. Se estableció y consolidó en los posgrados, y no en las licenciaturas, por una decisión consciente y deliberada. Las escasas feministas que había en la universidad en la década de 1970 y 1980 buscaron la mejor manera de introducir el feminismo en la currícula. Desde la pequeñez que representa el pensamiento feminista en la academia, desde la debilidad y la marginación se optó por introducirlo en las licenciaturas aunque fuera de manera parcial, convencidas de que ahí (con suerte) no pasaría de ser un parche a menudo torpemente adherido. No ha sido posible cambiar las disciplinas de raíz porque están dominadas por académicos/as que las quieren tal como están, totalmente androcéntricas. Con respecto a las licenciaturas se tenían enfrente, entonces, dos posibilidades: 1) Crear un programa de licenciatura totalmente nuevo en Estudios de la Mujer o 2) Salpicar de alguna idea o tema feminista cual pegote, ciertos espacios, como un añadido y nada más, quedando la carrera igual que antes sin verse realmente transformada. Se optó por la segunda.

Ahora bien, la docencia sobre las mujeres y las relaciones entre los géneros es mejor que se ubique en los posgrados cuando ya se ha adquirido una formación disciplinaria dado que esta investigación y docencia tiende a ser pluridisciplinaria. En ese ámbito, siendo pocas, se han podido crear programas fuertes y consolidados. Y a eso nos abocamos. En los programas de posgrado en donde se tiene el control casi absoluto sobre la docencia que se imparte. Desde ahí se realiza, asimismo, la investigación y la difusión. Y, sin embargo, no hay duda de que en gran medida lo que hacemos es ignorado. La mayoría de colegas no feministas en la academia no leen prácticamente nada que provenga del feminismo. Hay una deliberada y sistemática marginación, un ninguneo, aunque no siempre tienen el éxito deseado.

Si la investigación feminista avanza es por obra y gracia de las propias mujeres (y los escasos varones) que investigan en los diferentes ámbitos. Quiero decir, no es precisamente porque desde las instituciones se abran puertas sin que se haya tratado de abrirlas previamente. Los espacios se han ido creando solamente porque las investigadoras los han propiciado.

Hace un par de décadas consideraba que el relevo generacional feminista, tanto en el activismo como en la academia, era problemático. Sin embargo, hoy en día pienso que el relevo se encuentra asegurado. Las jóvenes se han volcado masivamente al activismo feminista dentro de distintos ámbitos y, asimismo, hay ya un relevo en la academia. Con gran satisfacción he comprobado que las y los jóvenes están haciendo Momento: diálogos em educação, E-ISSN 2316-3100, v. 28, n. 3, p. 337-349, set./dez, 2018. 
movimiento. Hará unos diez años se creó, por ejemplo, la 1era. Escuela de Formación Juvenil Feminista organizada por "El grito de las Brujas" (sólo mujeres) y "Elige" (sólo jóvenes y mixto). También una organización, "Decidir", que se auto-denominó Coalición de Jóvenes por la Ciudadanía Sexual. ¿Será que de nueva cuenta es preciso desconfiar de toda persona mayor de 30? Lo cierto es que la riqueza dentro del movimiento es hoy en día sustantiva tanto en México como en el resto de Nuestra América y, sobre todo, como dije, que el relevo generacional es un hecho visible. Es importante, sin embargo, desear que se de una continuidad, con rupturas seguramente, pero continuidad al fin. Las jóvenes están integrándose tanto en el movimiento feminista como en las instituciones gubernamentales, no gubernamentales y en la academia. Y, además, subrayando su juventud. Hoy se hace gala de ello por doquier y se marca así la diferencia. Esto es nuevo. En las décadas de 1970 y 80, en pleno neofeminismo, no se hacía hincapié en lo joven, tal vez porque no había generación feminista precedente de la cual hubiera que diferenciarse, solamente había unas cuantas integrantes del movimiento que eran algunos años mayores que la inmensa mayoría.

Retomando lo que he dicho, creo que hace falta que se consoliden los posgrados en Estudios Feministas en México pues la pobreza en el campo de la docencia es grande. Simplemente no se avanza de manera significativa si bien debo decir que en la universidad autónoma Metropolitana-Xochimilco se abrió este año de 2018 un Doctorado en Estudios Feministas. Sin embargo, se puede pensar en tres razones que impiden la proliferación de estos programas de estudio:

1) Porque las autoridades no consideran que es necesario y obstaculizan o no facilitan (para decirlo más suavemente) su creación;

2) Por no contar con recursos humanos y/o económicos suficientes; y si se cuenta con ellos,

3) Porque las propias académicas consideran que su creación no es realmente importante. Se tiene un miedo legítimo ante la ilegitimidad de un campo de estudios relativamente nuevo como éste.

En el campo de la investigación se puede ver que hay gran variedad de trabajos sobre mujeres y relaciones entre los géneros, unos feministas y otros no. Cuestión ésta siempre debatible y debatida la de qué es una investigación feminista, pero estoy convencida de que existen diferencias y de que no debemos asustarnos con el fantasma del famoso feministómetro (del cual se hablaba bastante hace algún tiempo) que para lo Momento: diálogos em educação, E-ISSN 2316-3100, v. 28, n. 3, p. 337-349, set./dez, 2018. 
que ha servido, en realidad, es para amedrentar y paralizar.

Es muy notorio que las temáticas a investigar han ido cambiando con los años. En las décadas de 1970 y 1980 los intereses principales eran, desde la historia y la antropología, conocer el papel de las mujeres a lo largo justamente de la historia y las culturas; se trataba fundamentalmente de tareas de rescate. Además, se investigaron temas relacionados con la familia y el trabajo doméstico no asalariado, así como a las mujeres en el ámbito de la esfera laboral urbana y rural. Hoy en día se quiere estudiar casi en primer lugar la violencia hacia las mujeres en todas sus formas incluida la que denominan hoy "violencia doméstica" (ese otro eufemismo para no decir mujeres maltratadas o golpeadas porque se considera más incluyente), y el feminicidio, el horror que sólo investigan algunas feministas y algún investigador sensible a la problemática, pero no las autoridades. También se estudia migración femenina y participación política. En un segundo término tenemos a la salud reproductiva y la sexualidad. Luego estarían temas como medio ambiente y maternidad. Por último, los de ciencias y artes. Como puede verse, los intereses se han modificado.

Otro gran reto dentro de los estudios feministas representa la ausencia de investigación teórica. Se hacen investigaciones puntuales sobre alguna cuestión bien específica de la realidad, pero no hay prácticamente nada en cuanto a elaboraciones teóricas. El feminismo anglosajón, francés, italiano, alemán... lleva a cabo todo tipo de reflexiones teóricas, aquí en Nuestra América no. Éste, creo yo, es el reto mayor para el pensamiento feminista, para la producción científica de alto nivel, en México y en toda América Latina y el Caribe. Si no creamos nuestra propia investigación teórica, si no reflexionamos sobre nuestra realidad tenemos que vivir siempre de prestado. Todos, todos, absolutamente todos los marcos teóricos y conceptuales que se elaboran son con base en teorías de feministas de afuera. Y para acabarla de amolar, la poca teoría que se realiza en la región, en español, es ignorada por colegas mujeres y hombres. Pecamos de un horrible malinchismo. Y con ello no pretendo instalarme en un chovinismo barato, pero sería importante hacer el esfuerzo sistemático de revisión bibliográfica de lo que se produce en nuestros países, también. No se nos da de manera espontánea, hay que hacer el esfuerzo deliberado. Creo que eso ayudaría al desarrollo de la teoría en la región y es algo que nos lo debemos.

Al mismo tiempo, me he preguntado sobre las razones de esta escasa producción teórica feminista en la región. Evidentemente no es porque seamos subdesarrolladas intelectualmente y que por ello no elaboramos teorías o reflexiones filosóficas. Se trata Momento: diálogos em educação, E-ISSN 2316-3100, v. 28, n. 3, p. 337-349, set./dez, 2018. 
de una cuestión ante la cual aparecen varias explicaciones posibles: la propia opresión y situación de subalternidad en que han vivido las mujeres ha hecho que no nos consideremos capaces de un pensamiento abstracto, capaces de crear pensamiento teórico y filosófico, tenemos muy interiorizado el hecho de que son los hombres quienes desarrollan estas cuestiones; otra razón es que en una región con tantas necesidades apremiantes en nuestras sociedades se prioriza el conocimiento de problemas puntuales muy agudos hacia las mujeres con la finalidad de resolverlos cuanto antes; también está pesando el rechazo que se ha desatado ante las generalizaciones - y en teoría a menudo se trabaja con abstracciones que aparecen como generalizaciones - porque estamos influidas por el quehacer norteamericano en la academia que privilegia la investigación concreta de la realidad, aunque allá sí que se elabora, además, teoría. Otra razón es tal vez de carácter económico. En nuestra región hay una carencia enorme en cuanto a grande bibliotecas o acervos de publicaciones de todo el mundo. Por lo tanto, la información de lo que se produce en otras partes nos llega de manera tardía, cara y escasa. Éstas pueden ser algunas de las razones, pero debe de haber más.

La creación de las redes es de suma importancia sobre todo cuando no son producto de arriba, cuando no son resultado de una decisión de escritorio por parte de las direcciones de las instituciones en sus diversas naturalezas.

Dice con razón María Luisa Tarrés a modo de conclusión de un texto suyo que lo que "interesa destacar radica en la urgencia de aplicar la crítica sistemática no sólo a las prácticas, teorías o disciplinas académicas tradicionales, sino también a las prácticas, a las actividades y a las agendas propias" (Tarrés, 2001, 133). Es crucial nunca desprenderse de la crítica.

Se puede vislumbrar entonces que, por un lado, se ha consolidando la dictadura del género - dentro y fuera de la academia - especialmente en el mundo de la política formal y de las instituciones de gobierno y, por el otro, se abren diversas posibilidades de lucha a partir de las necesidades de las mujeres jóvenes que conforman hoy a los "nuevos" sujetos sociales y que se hallan muy activas. Otras voces, otras acciones, se escucharán y se verán a partir de las distintas realidades de las mujeres que, a pesar de tantas décadas de luchas feministas, siguen padeciendo el sexismo o francamente la misoginia.

La universidad que tenemos ahora ya no es más la universidad del siglo XX sino 
la de un nuevo siglo y la de un nuevo milenio. Es preciso pensar bien qué universidades necesitan nuestros países para contribuir a la creación de una sociedad con más equidad y justicia. Los desafíos son muchos y debemos enfrentarlos para hacer de ellas instituciones que cumplan cabalmente con los retos que se nos presentan. Una de las maneras que considero idónea es la de abrir espacios de posgrado en estudios feministas.

Nuestra universidad nació fragmentada, obedeciendo seguramente a razones políticas. Partida en cuatro conglomerado, (hoy ya son seis) y quebrada también en el interior de sus tres unidades académicas. Una de las tareas a la que nos hemos abocado las feministas en distintos momentos y desde diferentes espacios de la universidad, ha sido a buscar por diversos medios la comunicación y el trabajo coordinado. Son particularmente importantes los esfuerzos encaminados a estrechar los lazos entre los grupos de trabajo afines dentro de la institución. Y, por supuesto, no únicamente dentro de ella sino también fuera, con otras universidades del país y del extranjero, así como con organismos del gobierno y no gubernamentales. Una de las ventajas del desarrollo de las nuevas tecnologías es precisamente el de favorecer la comunicación y el intercambio de ideas, experiencias, procesos y resultados de investigación en una dimensión planetaria.

La autonomía es un concepto fundamental tanto para el movimiento feminista como para las instituciones de educación superior. Ésta debe de ser entendida en términos de libertad; la autonomía debe de ser un principio rector del quehacer. Autonomía no significa independencia, (las universidades autónomas no son independientes del Estado). Es preciso, por ello, conservar y desarrollar los puentes que se han ido creando entre los diversos grupos académicos que abordan la temática de mujeres, de género o feminista, entre los distintos espacios de conducción y entre los campos de difusión y comunicación y los miembros de la comunidad universitaria. Es necesario fortalecer el trabajo conjunto y en muchos casos crearlo, pero nunca en detrimento de la autonomía de pensamiento y de acción.

Por otro lado, ha sido crucial impulsar dentro de la universidad una política de equidad de género. Pienso que estamos aún muy lejos de lograrla, pero se han llevado a cabo avances significativos, así como en ciertos aspectos se percibe un estancamiento. De ahí la importancia académica, pero con implicaciones en lo político, de la creación de espacios de investigación y de docencia en el campo de los estudios de la mujer, de género o feministas. La UAM ha sido en esto vanguardia dentro de América Latina y el Momento: diálogos em educação, E-ISSN 2316-3100, v. 28, n. 3, p. 337-349, set./dez, 2018. 
Caribe, ya que cuando en un país como los Estados Unidos los centros y programas de estudios de la mujer se contaban por centenares, en la región latinoamericana y caribeña los de la UAM eran de los pocos que había... y escasos siguen siendo. En este campo somos algo así como la vanguardia de la retaguardia. Por lo que se refiere a la investigación sobre las mujeres y las relaciones entre los géneros nuestra universidad, sin lugar a dudas, ocupa un lugar destacado desde hace años.

Las mujeres entraron masivamente en la universidad, sobre todo a partir de la década de 1960 del siglo XX, en las carreras femeninas, eso sí, y desde ahí han ido feminizando a la universidad entera. Sin embargo, los puestos de dirección, de conducción, siguen estando fundamentalmente en manos de los varones, las mujeres aún no han entrado ahí en igualdad de condiciones. Una de las tareas hoy es participar en los espacios de liderazgo académico. Lo cual no quiere decir, de ninguna manera, que las mujeres - por el sólo hecho de serlo - deban de ser nombradas para un cargo, cualquiera que este sea. En lo personal, el sistema de cuotas con miras a proteger a los sectores marginados de la sociedad, aquí y en cualquier otra parte del mundo, no me ha parecido nunca la forma idónea de proceder. Desde luego que a las mujeres nos va a costar mucho más trabajo lograr lo mismo - por el rezago social de solamente unos cuatro mil años. Dicho de otra manera, en condiciones de igualdad de méritos entre un hombre y una mujer para ocupar un puesto, me inclinaría, sin lugar a dudas, por la mujer, para con ello contribuir a disminuir la desigualdad entre los géneros. Sin embargo, si el hombre tuviera más méritos y fuera políticamente progresista y crítico, debería de quedar él. La apuesta en favor de las mujeres debe de ser también una apuesta por la inteligencia, la creatividad y el bien social. Como dijo la pensadora inglesa Mary Evans: "La reorganización de la universidad con el objetivo de permitir la diversidad y la diferencia es así un campo de juego muy importante para el feminismo. Un gran lienzo que ofrece posibilidades de producir un conocimiento del mundo basado en una experiencia compartida" ${ }^{\text {. }}$

Y las universidades son precisamente espacios privilegiados en donde se desarrolla la inteligencia y se pone al servicio de la sociedad, pero de una sociedad dividida en clases por lo que a menudo las clases privilegiadas son las más beneficiadas. Enseñamos y aprendemos todos los días a pensar. En buena medida, se aspira a que este pensamiento sea crítico y contribuya así a mover las conciencias con

\footnotetext{
${ }^{3}$ Evans, 1997, pp. 196-197.

Momento: diálogos em educação, E-ISSN 2316-3100, v. 28, n. 3, p. 337-349, set./dez, 2018.
} 
tendencia a la momificación. Ha corrido ya mucha tinta sobre el proyecto de una educación de "excelencia" dentro de las universidades. Pienso que ese proyecto ha quedado a menudo reducido a una retórica administrativa, a un incremento de la competencia y el individualismo, pero vacío de contenidos socialmente significativos.

Quisiera mencionar aquí el papel nodal de las humanidades dentro de la academia. Es necesario tomar en serio el páramo en el que se encuentran estas en la sociedad en general y dentro de las universidades en particular. En años recientes la política neoliberal ha puesto en tela de juicio el valor de las humanidades ya que hoy se busca, más que nunca, resultados inmediatos y palpables de las ciencias a favor de un desarrollo tecnológico. A fin de cuentas vivimos en una tecnocracia. Quizá lo que ofrecen las humanidades es precisamente la capacidad de entender la naturaleza sistémica de las cosas o, parafraseando al pensador también inglés Gregory Bateson, se puede ver que la racionalidad simple y pragmática sin la ayuda del arte, la filosofía, los sueños y similares - la materia prima de las humanidades - es necesariamente patógena y destructiva de la vida. La vida depende de circuitos interconectados de contingencia, pero la conciencia inmediatista sólo percibe los arcos cortos de esos circuitos a los que se dirige. Este es el mundo en el cual vivimos. Un mundo de estructuras de circuitos donde el amor puede sobrevivir frente al odio, si la sabiduría, o sea el reconocimiento del hecho de que todo está interconectado, tiene una voz efectiva. ${ }^{4}$

Puede ser y es ya un lugar común e incluso un tópico, la necesaria defensa de la universidad pública en Nuestra América. Peligra, hace rato que está peligrando, y es preciso conjuntar esfuerzos para su permanencia. Creo que es una cuestión que, junto con el sistema de salud pública, constituyen dos de los pilares fundamentales surgidos para amortiguar los efectos de las grandes desigualdades económicas. Es preciso no perderlos.

Nuestras universidades serán sobresalientes en cuanto a la generación de nuevas ideas y conocimientos desde cualquier disciplina en este mundo globalizado, si tienen asegurados los fondos necesarios no sólo para subsistir, sino para llevar a cabo la investigación de alto nivel que se requiere. Una cuestión vital para asegurar la calidad son los recursos financieros. De todos modos, es sabido que el presupuesto destinado a la educación superior es siempre insuficiente y a menudo menguante. Resulta indispensable obtener más recursos o muy pronto la universidad pública se verá

\footnotetext{
${ }^{4}$ Bateson, 1972, p. 147.

Momento: diálogos em educação, E-ISSN 2316-3100, v. 28, n. 3, p. 337-349, set./dez, 2018.
} 
reducida a su mínima expresión.

\section{REFERENCIAS}

Bateson, Gregory. (1972). Steps to an Ecology of Mind. Nueva York: Ballantine Books.

De Oliveira, Orlandina y Marina Ariza. (1999). "Un recorrido por los estudios de género en México: consideraciones sobre áreas prioritarias", (Versión preliminar para discusión), Taller "Género y Desarrollo", Oficina Regional para América Latina y el Caribe CIID/IDRC, Montevideo.

Evans, Mary. (1997). "Feminismo y universidad" en Introducción al pensamiento feminista contemporáneo, Madrid, Minerva ediciones.

Tarrés, María Luisa. (2001). "De la necesidad de una postura crítica en los estudios de género", La Ventana, 13, pp. 107-136. 